\title{
ANALISANDO A CONCEPÇÃO DE EDUCAÇÃO INTEGRAL DO GOVERNO LULA/DILMA ATRAVÉS DO PROGRAMA MAIS EDUCAÇÃO
}

Jamerson Antonio de Almeida da Silva* Katharine Ninive Pinto Silva**

RESUMO: Este artigo analisa a concepção de Educação Integral que orienta o Programa Mais Educaşão, "nova estratégia" do Governo Federal para a promoção da "educação integral em tempo integral" na escola pública brasileira. Através da análise dos principais documentos que fundamentam o programa, constatamos a proposição de uma Educação Integral Intercultural, assentada numa Gestão Intersetorial e Sistêmica. Desvelamos, então, uma renovação pós-moderna/pós-estruturalista do escolanovismo pragmatista presente no Programa; uma renovação da teoria do capital humano na forma de uma Pedagogia das Competências, ou neotecnicismo e, no plano da gestão sistêmica e intersetorial, o transplante do modelo empresarial de reorganização do trabalho (Teoria da Qualidade Total) para o âmbito do sistema educacional. Concluímos que essa é uma expressão particular e contraditória da subordinação intelectual e moral do Governo Lula/Dilma ao neoliberalismo, revelando-se como a expressão da "hegemonia às avessas" no âmbito da política educacional.

Palavras-chave: Educação Integral; Pós-modernismo; Neoliberalismo.

* Doutor em Educação pela Universidade Federal da Bahia (UFBA); Docente do Programa de Pós-Graduação em Educação Contemporânea e do Núcleo de Formação Docente do Centro Acadêmico do Agreste - Universidade Federal de Pernambuco (UFPE). E-mail: jamersonufpe@gmail.com.

* * Doutora em Educação pela Universidade Federal da Bahia (UFBA); Docente do Programa de Pós-Graduação em Educação Contemporânea e do Núcleo de Formação Docente do Centro Acadêmico do Agreste - Universidade Federal de Pernambuco (UFPE). E-mail: katharineninive@yahoo.com.br. 


\section{ANALYZING THE CONCEPT OF INTEGRAL EDUCATION OF GOVERNMENT LULA/DILMA THROUGH PROGRAM MORE EDUCATION}

ABSTRACT: This article analyzes the concept of Integral Education that guides the program named More Education, "a new strategy" of the Brazilian Federal Government for the promotion of "full time education" at the Brazilian public schools. Through the analysis of key documents underpinning the program, it has been found the proposition of an Integral Intercultural Education, based on an Intersectoral and Systemic Management Model. It was also revealed a renewal of postmodern/poststructuralist of the pragmatic escolanovismo (newschoolism) in this Program; a renewal of human capital theory as a Pedagogy Skills, or neo-technicism and, in terms of intersectoral and systemic management planning, the transplantation of work reorganization business model (Theory of Total Quality) to the scope of the educational system. We have concluded that this is a particular expression of moral and intellectual subordination of the government Lula / Dilma to neoliberalism, revealing itself as the expression of "reverse hegemony" as part of the educational policy.

Keywords: Full Time Education; Postmodernism; Neoliberalism.

\section{Introdução}

Como ação prevista pelo Plano de Desenvolvimento da Educação (PDE), instituído através da Portaria Interministerial $\mathrm{n}^{\circ} 17$ (BRASIL, 2007c) e regulado através do Decreto $n^{\circ} 7.083$ (BRASIL, 2010b), o Programa Mais Educação, principal ação do Governo Federal para indução da ampliação da jornada escolar nas escolas públicas, busca sustentação jurídica em ampla legislação. ${ }^{1}$ Além deste, outros projetos jurídico-institucionais que estão em tramitação no Congresso Nacional expressam a intenção dos poderes Executivo e Legislativo de fortalecer a atual política de educação (em tempo) integral que, ao nosso ver, altera significativamente a organização da educação básica no Brasil.

De iniciativa do Poder Executivo, destacamos o Projeto de Lei no 8.035/2010, o Plano Nacional de Educação (PNE-2011/2020), que prevê a oferta de educação em tempo integral, para 50\% das escolas públicas de educação básica até 2020. Já o Poder Legislativo vem debatendo, desde 2007, a Proposta de Emenda Constitucional (PEC) de $n^{\circ}$ $134 / 07,{ }^{2}$ que visa a obrigar o governo a ampliar a jornada escolar de toda a educação básica para o mínimo de sete horas diárias até o ano de 2020. O ponto comum de ambos os projetos é tomar como principal modelo para tal mudança o Programa Mais Educação. 
Dessa forma, este artigo tem por objetivo analisar a concepção de Educação Integral que orienta o Programa Mais Educação, buscando desvelar os fundamentos teóricos que constituem seu referencial normativo, os quais expressam os fins político-sociais do programa, a organização curricular e seu modelo de gestão. Conforme Muller (1985), o referencial normativo de uma política traduz as concepções dominantes a respeito de um setor, profissão ou disciplina. O referencial normativo setorial articula-se a um projeto global que constitui seu sistema de dominação e a maneira como se dá a articulação dos interesses sociais nesse contexto, revelando uma função econômica atribuída à política ou programa.

Metodologicamente, valemo-nos da análise documental de textos legais e dos Cadernos Série Mais Educação, entendendo que estes sintetizam a dimensão cognitiva e técnico-instrumental do Programa em questão. ${ }^{3}$ Vale salientar que o foco de análise na intencionalidade que constitui o projeto do Governo Federal não desconsidera que tais orientações podem sofrer, e sofrem, interdições e redirecionamentos, conforme os interesses políticos, econômicos, e o universo simbólico-cultural instituídos pelos poderes locais. A ênfase no governo Lula/Dilma justifica-se, entretanto, pelo interesse em analisar as idiossincrasias presentes no projeto anunciado pelo poder central, ao se propor a construir uma concepção contemporânea de educação integral.

\section{Uma concepção contemporânea de Educação Integral}

O Programa Mais Educação tem como um de seus pressupostos, presente no Plano de Desenvolvimento da Educação (PDE), a ideia de que o desenvolvimento nacional da educação é "eixo estruturante da ação do Estado", em torno da "[...] erradicação da pobreza e marginalização" (BRASIL, 2007a, p.6, grifo nosso). Nesse sentido, o Programa tem por objetivo:

[...] contribuir para a formação integral de crianças, adolescentes e jovens, por meio da articulação de ações, de projetos e de programas do Governo Federal e suas contribuições às propostas, visões e práticas curriculares das redes públicas de ensino e das escolas, alterando o ambiente escolar e ampliando a oferta de saberes, métodos, processos e conteúdos educativos (BRASIL, 2007c, p.2). 
Para orientar a implementação do Mais Educação nos estados e municípios, além da Portaria Interministerial no 17/2007 e do Decreto $\mathrm{n}^{\circ}$ 7.083/2010, o Ministério da Educação (MEC), através da Secretaria Nacional de Alfabetização, Formação Continuada e Diversidade (Secad), elaborou e publicou um conjunto de documentos através dos quais vêm sendo disseminados os princípios e fundamentos para a elaboração do projeto político-pedagógico, da proposta curricular e do modelo de gestão nos estados e municípios brasileiros. Os principais documentos são os Cadernos da Série Mais Educação: Programa Mais Educação: gestão intersetorial no território, Brasília - DF (BRASIL, 2009b); Educação Integral: texto referência para o debate nacional, Brasília - DF (BRASIL, 2009c); Rede de saberes Mais Educação: pressupostos para projetos pedagógicos de Educação Integral, Brasília - DF (BRASIL, 2009d). Outros documentos de apoio ${ }^{4}$ também têm sido divulgados pelo Ministério da Educação, contento relatos de experiências "exitosas" e referências teórico-práticas para construção do Mais Educação nos estados e municípios. Na análise documental, utilizamos os textos supracitados, por entendermos que estes condensam o referencial normativo setorial do programa, os quais passaremos a expor.

\section{Mais Educação ampliando as funções da escola}

Conforme a análise dos documentos oficiais, a decisão de retomar o ideal da Educação Integral no Brasil é contemporânea aos esforços do Estado para a oferta de políticas redistributivas de combate à pobreza. Para enfrentar a situação de "vulnerabilidade e risco social", de acordo com o texto governamental, a escola deve cumprir o duplo desafio de "proteger" e "educar" crianças, adolescentes e jovens por ela atendidos:

[...] Nesse duplo desafio - educação/proteção - no contexto de uma 'Educação Integral em Tempo Integral' ampliam-se as possibilidades de atendimento, cabendo à escola assumir uma abrangência que, para uns, a desfigura e, para outros, a consolida como espaço realmente democrático (BRASIL, 2009d, p.17).

Assim, o Mais Educação atribui à escola uma enorme gama de finalidades, as quais abrangem: 
[...] a "ampliação do tempo e do espaço educativo e a extensão do ambiente escolar"; combater "evasão escolar, a reprovação e a distorção idade/série"; promover o "atendimento educacional especializado" às crianças com "necessidades educacionais especiais"; prevenir e combater o trabalho infantil, a exploração sexual e outras formas de violência contra crianças, adolescentes e jovens"; promover a formação da "sensibilidade, da percepção e da expressão de crianças, adolescentes e jovens nas linguagens artísticas, literárias e estéticas"; estimular as práticas corporais, educacionais e de lazer"; "promover a aproximação entre a escola, as famílias e as comunidades"; e "prestar assistência técnica e conceitual aos entes federados" com vistas à operacionalização da portaria que implementa o programa (BRASIL, 2007c, p.2).

Notadamente, ampliando-se as funções da escola, ampliam-se também as tarefas dos educadores. "Esse conjunto de elementos desafia a uma nova postura profissional que deve ser construída por meio de processos formativos permanentes" (BRASIL, 2009d, p.17). O mesmo documento reconhece que uma política de educação integral "[...] pressupõe uma consistente valorização profissional, a ser garantida pelos gestores públicos, de modo a permitir dedicação exclusiva e qualificada à educação" (BRASIL, 2009d, p.39). Para tanto, também seria necessária a regulamentação do Piso Salarial Nacional Profissional; incremento no financiamento da educação e "[...] ampliação dos investimentos públicos em educação, de modo a alcançar o mínimo de 7\% do PIB até 2021" (BRASIL, 2009d, p.40). Vale evidenciar que as condições acima, destacadas como cruciais ao sucesso do Programa, segundo o governo central, ficam na dependência de um alinhamento político que efetive o regime de colaboração entre o Governo Federal, estados e municípios. Ou seja, não são critérios para implementação do Programa, mas apenas uma recomendação do que deveria ser a médio e longo prazo.

\section{Educação Integral Intercultural}

Reconhecendo que existem diversas matrizes teóricas que fundamentam o conceito de Educação Integral, na definição apresentada no documento, a Educação Integral do Programa aparece como a "formação mais completa possível" para o ser humano. Orientando tal concepção, o Programa Mais Educação propõe a elaboração de um quadro conceitual 
mais amplo, no qual a pactuação da qualidade considere o valor das diferenças. Para tanto, a proposta busca inspiração nos Estudos Culturais, a partir das ideias de antropólogos e pensadores da cultura contemporânea que, conforme o documento analisado, ajudam a compreender as condições atuais das trocas culturais, pensando o problema a partir da interrelação entre culturas, dentre eles, “[...] Nestor Cancline, Clifford Geertz, Pierre Bourdieu, Michel Focault, Boaventura de Souza Santos e Umberto Eco" (BRASIL, 2009c, p.20). Na área de educação, encontramos referências a intelectuais que compõem o pensamento pedagógico brasileiro, tais como Paulo Freire, Vera Maria Candau, Moacir Gadotti, Paulo Roberto Padilha, Jaquelline Moll, entre outros. Nesse horizonte teórico, o Mais Educação propõe uma Educação Integral Intercultural, pressupondo que:

A interculturalidade remete ao encontro e ao entrelaçamento, àquilo que acontece quando os grupos entram em relação de trocas. Os contextos interculturais permitem que os diferentes sejam o que realmente são nas relações de negociação, conflito e reciprocidade. Escola e comunidade são desafiadas a se expandirem uma em direção a outra e se completarem (BRASIL, 2009d, p.21).

A proposta central, conforme o documento supracitado é a de que o currículo parta das diferentes realidades, possibilitando o diálogo entre as diferentes culturas, relacionando os "saberes comunitários" com os "saberes escolares". Como forma de superar essa oposição entre diferentes formas de saberes, o Programa Mais Educação lança mão do pensamento de Santos (2008) para defender que, através do diálogo, seja possível avançar na formulação de um pensamento síntese, capaz de fazer desaparecer a distinção entre o conhecimento científico e o cotidiano (BRASIL, 2009d, p.28).

Em relação à organização curricular, o Mais Educação busca inspiração nas ideias de Umberto Eco (1962), de que o processo pedagógico criador é semelhante a uma obra aberta, e apresenta a "Mandala de saberes" como instrumento pedagógico capaz de produzir um processo pedagógico que "[...] se abre para que diferentes sujeitos possam escolher suas condições, sequências e formas, transformando a prática educacional em espaço de diálogo e negociação, ou talvez de criação" (BRASIL, 2009d, p.28).

Em relação às questões dos espaços e tempos escolares, o Programa propõe a superação de possíveis ideias de "hiperescolarização" 
ou de escola como uma Instituição Total (FOUCAULT, 1987), apontando, como alternativa, ações inspiradas no movimento de Cidades Educadoras, propondo a descoberta de novos Territórios Educativos, para além dos muros da escola, no bairro e na cidade, que, em parceria com "redes sociais" e diversos sujeitos educadores, realizem esse amplo processo de "educar" e "proteger".

De acordo com o Programa, a educação comunitária é entendida como a forma de agregar a sociedade em torno do processo educativo,

[...] ao pactuar com ela esse compromisso; identificar referências; realizar diagnóstico do território; mapear oportunidades e parceiros; construir e gerir trilhas educativas - escolares, complementares e de apoio (BRASIL, 2008, p.11).

Por meio de Trilhas Educativas, são percursos nos quais os processos pedagógicos se dão, para além dos muros da escola, o que inclui as praças, parques, ateliês, becos, estúdios, oficinas, empresas, museus, teatros, cinemas, parques de diversão, centros esportivos, bibliotecas, livrarias, etc.

\section{Gestão intersetorial no território}

A sistematização da proposta de Gestão do Mais Educação consta no documento Programa Mais Educação: gestão intersetorial no território (BRASIL, 2009b). Entretanto, analisando a Portaria Interministerial $n^{\circ}$ 17/2007 (que institui o Programa), Pinheiro (2009) descobre os termos "ações integradas" e "intersetorialidade" como duas categorias que informam a gestão inovadora e democrática do Programa. A primeira categoria refere-se à necessidade de participação da sociedade na educação, as parcerias com a família, com a comunidade, sociedade civil, organizações não governamentais. A segunda, à necessidade de articulação interministerial e das políticas públicas locais visando a proporcionar novas oportunidades educativas.

Para o governo, a gestão intersetorial surge como possibilidade de troca, podendo trazer mais qualidade para a educação, tendo em vista permitir a superação de fronteiras. No âmbito municipal, ter esse novo princípio de gestão sugere que cada um poderá participar da definição de seus 
critérios de implementação, de acordo com a importância que se tem em cada realidade. Para que a gestão intersetorial ocorra, é necessária a "governança", ou seja, "[...] a capacidade de comando e de direção" e ainda de implementação, requerendo do Estado as competências para articular os diversos atores envolvidos com poder e legitimidade para fortalecer contextos democráticos e fazer com que "[...] se possam alcançar objetivos comuns a um menor custo, o que potencializa novas ações" (BRASIL, 2009b, p.43).

É importante destacar que, visando à melhoria da qualidade da educação, o Índice de Desenvolvimento da Educação Básica (IDEB) é a principal referência de avaliação do Programa Mais Educação, sendo também um dos principais critérios para escolha das escolas. Vale ressaltar que tal escolha implica a destinação de recursos federais aos estados, municípios e Distrito Federal. Em relação ao financiamento dos programas locais, a liberação dos recursos está condicionada à assinatura dos termos da proposta de operacionalização do PDE, o Plano de Metas Compromisso Todos pela Educação, ${ }^{5}$ que analisaremos mais adiante.

\section{Analisando a Educação Integral no Mais Educação}

Após a apresentação das bases que orientam o Programa Mais Educação, passemos ao desvelamento dos alicerces que orientam sua concepção de Educação Integral, através da análise do projeto político-pedagógico, da organização curricular e do modelo de gestão.

\section{Proteger para educar ou mais "coisas" através da escola?}

Em relação à função de "proteger" e "educar”, o Governo Federal apresenta essa dupla função como necessidade de uma realidade recente, visando atender a um público em situação de vulnerabilidade social, através de ações integradas com as áreas de saúde, assistência social, esporte e lazer, sem as quais o processo de escolarização seria inviável.

A análise crítica dessa proposição requer destacarmos, em primeiro lutar, que o artifício da utilização do equipamento escolar para a realização de outras políticas sociais não é uma "necessidade recente", 
podendo-se observar, na história da educação do país, uma progressiva ampliação das tarefas da escola pública, passando esta a assumir funções de outras modalidades da política social.

Nessa perspectiva, ainda em 1983, ${ }^{6}$ Saviani denominou esse "fenômeno" como "educação compensatória", segundo a qual, para a escola cumprir sua função equalizadora, "[...] é necessário compensar as deficiências cuja persistência acaba sistematicamente por neutralizar a eficácia da ação pedagógica" (SAVIANI, 2008, p.27). A estratégia de alargamento das funções da escola, nesse contexto, também fora explicitada pelo autor sob a classificação de "perspectiva redentora da educação".

Por sua vez, Algebaile (2009) lembra que, nos anos 1980, algumas propostas de escolas de tempo integral seriam exemplos extremos da recriação da escola pública, com base em uma "concepção ampliada" do espaço e das "funções escolares". Naquele momento, a ideia de uma escola de qualidade para os pobres não seria a expansão do modelo escolar das elites para toda a rede, e sim a expansão para a realização de mais coisas através da escola.

No cenário de hegemonia neoliberal, a ampliação das funções da escola, incorporando tarefas de "proteção social", é uma expressão do aprofundamento da redução das políticas sociais que transformam a escola pública brasileira em uma espécie de "posto avançado do Estado", utilizada para garantir certas condições de controle populacional e territorial, formas variadas de negociação do poder em diferentes escalas e certa "economia de presença" em outros âmbitos da vida social" (ALGEBAILE, 2009). É importante salientar, ainda, que essa tarefa de "proteção", como expressão ampliada das tarefas da escola, corresponde a encurtamentos na esfera pública, em pelo menos dois sentidos, "[...] relativos às reduções operadas na política social e nas dimensões e condições formativas da escola" (ALGEBAILE, 2009, p.27).

Por outro lado, considerando a política educacional como uma modalidade de política social que está inserida em um projeto político mais amplo, é importante que se considere o seu espaço no quadro desse projeto maior. Analisando o governo Lula, Filgueiras e Gonçalves (2007) afirmam que as orientações teórico-metodológicas das políticas sociais, naquela gestão, e continuadas na gestão Dilma, abandonaram os direitos universais: 
[...] com a extinção de direitos, as políticas sociais universais, que exigem volume maior de recursos financeiros, são substituídas por políticas focalizadas, que exigem recursos financeiros para obter superávits fiscais primários e pagar juros da dívida pública (FILGUEIRAS; GONÇALVES, 2007, p.146).

Dessa forma, é preciso considerar também o fato de o Governo Federal se colocar na posição de apenas "indutor" do Programa Mais Educação, responsabilizando os estados e municípios pelo provimento das condições, as quais julga cruciais ao sucesso da iniciativa, como a valorização docente, a regulamentação do piso salarial e o incremento do financiamento. Mesmo não ignorando que cada ente federativo tem atribuições e responsabilidades constitucionais específicas no que se refere ao financiamento das políticas educacionais, o fato de a valorização do trabalho docente não ser um critério para a implantação do Programa, juntamente com os precários dispositivos criados para garantir o funcionamento da jornada ampliada nas escolas, nos leva a considerar essa função indutora como uma faceta do processo de desobrigação da União no que se refere às políticas sociais, em sintonia com a concepção anteriormente mencionada. Um exemplo disso é a utilização do artifício do voluntariado pelo Programa, como uma "indução" à precarização e à desprofissionalização do trabalho docente.

\section{Educação Intercultural e pós-modernismo}

O conceito de Educação Integral Intercultural que orienta o Programa Mais Educação fundamenta-se nos estudos culturais, conforme evidenciamos na análise documental. Para Barker e Bezzer (1994), os estudos culturais não consideram o conceito de "classe" como uma ideia central, passando a ser, na melhor das hipóteses, uma variável, entendido agora como, no máximo, um modo de opressão, de pobreza.

No que se refere à relação entre cultura e política, tais estudos são marcados por um reducionismo de variedade culturalista que subordina a política à cultura, dando centralidade às "diferenças culturais", através da forte influência do pensamento pós-moderno. É a partir da centralidade política que as "diferenças culturais" passam a adquirir que o multiculturalismo ganha status de "condição da realidade" e projeto de intervenção política e pedagógica. 
O Programa Mais Educaşão busca inspiração na centralidade das diferenças culturais e na ressignificação de elaborações do escolanovismo pragmatista de Dewey e Anísio Teixeira, sobretudo considerando a questão das diferenças e da pluralidade nesse tipo de formulação. Partindo de uma análise no campo sociológico, Teixeira (1924) abordou a questão das diferenças no livro A propósito da Escola Única, enfatizando a impossibilidade do ensino único em uma sociedade complexa e de naturezas diversas.

Portanto, evidencia-se, na concepção de Educação Integral do Mais Educação, uma certa aproximação com o pragmatismo de Anísio Teixeira, sendo que o tema da "diferença" e da "diversidade" assumem agora um tom pós-moderno (pós-estruturalista) dos denominados estudos culturais.

A busca incessante das diferenças no processo de produção do conhecimento, apesar do hibridismo pós-moderno, fundamenta-se em um antiessencialismo filosófico, na negação da totalidade, na indeterminação social e no anti-humanismo (MALIK, 1999). De acordo com Eagleton, a filosofia pósmoderna,

[...] é uma linha de pensamento que questiona as noções clássicas de verdade e razão, identidade e objetividade, a ideia de progresso ou emancipação universal, os sistemas únicos, as grandes narrativas ou os fundamentos definitivos de explicação. Contrariando essas normas do iluminismo, vê o mundo como contingente, gratuito, diverso, instável, imprevisível, um conjunto de culturas ou interpretações desunificadas, gerando um certo grau de ceticismo em relação à objetividade da verdade, da história e das normas, em relação às idiossincrasias e à coerência de identidades (EAGLETON, 1998, p.7).

Ao insistir que a sociedade é inerente e irredutivelmente heterogênea e diversificada e, ao rejeitar qualquer ideia de "totalidade", que poderia nos permitir ver, nos aspectos comuns, ligações entre os elementos heterogêneos e diversificados, o pensamento pós-moderno/pósestruturalista esgota sua própria capacidade de contestar as explicações naturalistas das diferenças. Assim, esse antiessencialismo pósmoderno/pós-estruturalista passa a se assemelhar ao empirismo radical dos positivistas que foram contestados.

Uma visão antropocêntrica predominou na revolução científica e filosófica desencadeada pela Renascença e pelo Iluminismo, tendo sido decisiva para todas as filosofias e movimentos políticos progressistas no 
Ocidente. Nessa perspectiva, o humanismo expressou variadas formas políticas que vão do liberalismo ao marxismo. Apesar dos antagonismos, conforme Malik (1999), duas crenças básicas são definidoras do humanismo: a de que os seres humanos possuem alguma coisa em comum (natureza humana) e a de que, mesmo sendo partes inerentes da natureza e sujeitos às suas leis, têm uma capacidade originada na razão e na sociabilidade humana de superar as restrições que lhes são impostas por essa natureza. Então, para os humanistas, subjacente a todas as correntes, há uma crença na emancipação humana, ou seja, a ideia de que a humanidade pode transformar racionalmente a sociedade através de seus próprios esforços. $\mathrm{Na}$ verdade, o resultado do anti-humanismo é a rejeição às ideias de igualdade e unidade humana, "louvando, ao invés disso, a diferença e a divergência, e exaltando o particular e o 'autêntico' em contraposição com o universal" (MALIK, 1999, p.134).

Por outro lado, o antiessencialismo e a negação de qualquer ideia de "totalidade" destroem a capacidade de vermos os aspectos comuns ou as ligações entre os elementos heterogêneos e diversificados. Esse tipo de indeterminação é próprio das explicações a-históricas da sociedade. Restringe, por exemplo, nossa capacidade de compreender a natureza histórica do capitalismo, como forma social específica. Nesse sentido, Wood afirma:

Mesmo em suas manifestações menos extremas, o pós-modernismo insiste na impossibilidade de qualquer política libertadora, baseada em algum tipo de conhecimento ou visão "totalizantes". Não se pode dizer sequer que o capitalismo, como sistema totalizante, exista no discurso pós-moderno - o que impossibilita a própria crítica ao capitalismo. [...] Embora haja projetos mais universais que, de fato, pareçam atraentes para esquerda pós-moderna, tal como a política ambiental, é difícil entender como eles - ou, na verdade, qualquer ação política - podem ser coerentes como os princípios mais fundamentais do pós-modernismo: um ceticismo epistemológico e um derrotismo político profundos (WOOD, 1999, p.13).

Essa incoerência está presente na proposta de Educação Integral Intercultural do Programa Mais Educação, coordenado pelos intelectuais petistas pós-modernos que assumem o discurso pós-moderno/pós-estruturalista da afirmação dos "diferentes" sujeitos identitários, sem questionar as determinações materiais que historicamente condicionaram as políticas de silenciamento e exclusão que buscam combater. 
Como já apontamos, o Mais Educação propõe uma "Educação Integral Intercultural", fundamentado no pensamento de Santos (1998), de maneira que suas ações possam articular políticas de redução das desigualdades e afirmação das diferenças. Nesse mesmo horizonte, intelectuais do Instituto Paulo Freire-SP, que influenciam a concepção de Educação Integral Intercultural, tais como Moacir Gadotti, Paulo Roberto Padilha, Ângela Antunes e Salete Valesan, definem que:

O conceito de interculturalidade é sinônimo de interação, troca e interdependência cultural. A diversidade é a grande riqueza da humanidade. Não existe hierarquia entre as culturas. Não se pode avaliar uma cultura com os pressupostos e os valores de uma outra cultura. O conceito de interculturalidade, diferente da multiculturalidade e da monoculturalidade, que tendem para o isolamento, traz uma carga de relações, princípios e valores baseados na horizontalidade e no diálogo. A interculturalidade pressupõe uma filosofia pluralista, uma atitude de escuta permanente e a da construção de sociedades plurais nas quais se reconhece e valoriza o direito à diferença. A interculturalidade favorece a superação da violência, cometida principalmente contra os mais pobres, os homossexuais, as mulheres, os negros, as crianças (GADOT'TI, 2009, p.103, grifo do autor).

Analisando a proposta de interculturalismo de Santos (1999), podemos perceber que este se fundamenta em um conceito de "democracia comunitarista". Tal conceito retoma a temática da diferença e da correlação entre o local e o geral e do apelo aos movimentos sociais. A solução comunitarista contra a escola monocultural é o interculturalismo, que pretende preservar a identidade local e negociar trocas com os outros diferentes. Contudo, no comunitarismo, o Estado não se define pela promoção do direito, mas é, sobretudo, o palco em que a luta pelo reconhecimento se expressa. Assim, como ocorre nas práticas afirmativas, diferença substantiva deve-se sobrepor à igualdade universal:

[...] essa atitude, muitas vezes relativista e pragmática, admite criar pontes e tornar fronteiras mais permeáveis, sem a intenção de buscar pontos de vistas comuns ou conversões mútuas, afirmando, assim, a diversidade. [...] a radicalização e fragmentação da visão comunitarista tem levado a um ceticismo em relação às possibilidades de negociação na escola. Como produzir acordos e consensos quando muitas comunidades, grupos e tribos são concebidos como singularidades, cujos valores são irredutíveis? (SILVA, 2009, p.164). 
Para Della Fonte (2011), sob essa lógica os valores culturais diversos são transformados em uma multiplicidade de verdades. No entanto, apesar do ímpeto anti-imperialista e anticolonialista, essas posturas relativistas beneficiam os grupos conservadores, cujos interesses podem, " [...] por um lado, ser criticados, quanto à sua pretensão de verdade universal; porém, por outro, são preservados à medida que, mesmo assim, possuem legitimidade e verdade contextual, podendo conviver e mesclar-se com outras narrativas culturais" (DELLA FONTE, 2011, p.35).

Entrelaçam-se a isso problemas de ordem ética e política, uma vez que a relativização da verdade também envolve o relativismo da própria justiça. É nesse horizonte de relativismo, anti-intelectualismo e ceticismo ontológico, no qual os conhecimentos são relativizados, que a educação escolar sofre um duro golpe. $\mathrm{Na}$ Educação Intercultural, o papel da escola é propiciar a crítica e a hibridização cultural, que consistem em desvelar qualquer pretensão de superioridade de uma narrativa e negociar dialogicamente os encontros e desencontros entre elas. Dessa forma, segundo Della Fonte (2011), o papel da escola fica reduzido à construção de sofismas.

Essa reconfiguração do papel da escola vem-se dar exatamente no momento em que o capitalismo vem revelando sua face mais perversa e sua impossibilidade de garantir uma vida digna a todos. Nesse momento, qualquer teoria que tenha a tarefa de desvendar facetas do mundo objetivo vem sendo combatida e desacreditada. Assim, "[...] a interdição do conhecimento objetivo e a redefinição do papel da escola compõem o mesmo processo de fortalecimento do capitalismo contemporâneo" (DELLA FONTE; LOUREIRO, 2011, p.189). Aceitar acriticamente a pluralidade de narrativas desqualifica a escola, o trabalho do professor, além de esfacelar o currículo, sobretudo da escola pública, através de esvaziamentos, reducionismos e/ou tentativas de transformar em consensos conflitos subjacentes e que passam a fazer parte do currículo oculto da escola. 


\section{Reconfigurando a pedagogia do "aprender a aprender"}

O lema "aprender a aprender" é outra característica central da pedagogia da Escola Nova, que é retomada também na proposta do Mais Educação. Saviani sintetiza o significado desse lema:

No âmbito do escolanovismo, "aprender a aprender" significava adquirir a capacidade de buscar conhecimento por si mesmo, de adaptar-se a uma sociedade que era entendida como um organismo em que cada indivíduo tinha um lugar e cumpria um papel determinado em benefício de todo o corpo social. Portanto, essa concepção estava animada do otimismo (a escola risonha e franca) próprio de uma economia em expansão em que a industrialização criaria uma situação de mudanças constantes, caminhando, como foi assinalado, em direção ao pleno emprego propiciado pelas políticas keynesianas (SAVIANI, 2011, p.432).

A centralidade do aluno no processo de ensino/aprendizagem e a ênfase na pesquisa, por contraposição ao ensino enfatizado pela educação tradicional, são as características principais da pedagogia do aprender a aprender. No Mais Educação, tais elaborações também se encontram justificando o programa quando o Ministério da Educação se refere às tarefas propriamente escolares.

De outro lado, estão os desafios escolares. Neste trabalho, abordamos a formação do estudante para além do currículo escolar, vinculando-a com instâncias mais gerais de sua trajetória: a conquista da pesquisa. Pensamos que é fundamental para o estudante desenvolver a curiosidade, o questionamento, a observação, hipóteses, descobrir, experimentar, identificar e distinguir, relacionar, classificar, sistematizar, criar, jogar, debater, comparar e concluir, entre outras experiências formadoras (BRASIL, 2009d, p.17, grifos nossos).

Ao criticar a pedagogia nova, Saviani (2008) destacou que a ênfase na pesquisa em relação ao ensino levou a uma relativização do processo de apropriação do conhecimento acumulado, causando uma desqualificação da escola pública. No contexto atual, esse lema foi reapresentado de maneira a constituir o que autores do pensamento histórico-crítico estão denominando como neoescolanovismo (DUARTE, 2001; DELLA FONTE, 2011; SAVIANI, 2011). Nesse caso, a pedagogia do "aprender a aprender" renasce no contexto da chamada "sociedade do conhecimento", de desemprego estrutural, instabilidade e precarização do trabalho, de 
"incertezas" resultantes das políticas neoliberais de redução do Estado e da reestruturação produtiva na direção ao "capitalismo flexível". Nesse horizonte, o "aprender a aprender" está relacionado à "[...] a necessidade constante de atualização exigida pela necessidade de ampliar a esfera da empregabilidade" (SAVIANI, 2011, p.423).

Essa nova visão foi propagada amplamente na década de 1990 pela sua forte presença no Relatório Jacques Delors publicado pela Unesco em 1996. No Brasil, foi publicado em 1998, com a apresentação do então Ministro da Educação Paulo Renato Costa Souza. No relatório intitulado Educaşão: um tesouro a descobrir, "afirma-se a exigência de uma educação ao longo da vida para responder ao desafio de um mundo em rápida transformação" (DELORS, 2006, p.13). A orientação desse relatório também contamina os Parâmetros Curriculares Nacionais (PCNs), elaborados pelo MEC, como referência para a montagem dos currículos de todas as escolas do país. Conforme Saviani (2011), as justificativas do "aprender a aprender" nos PCNs são as mesmas do Relatório Jaques Delors," apontando para um "alargamento do horizonte da educação", no qual a escola deve ganhar novas competências, pois "[...] novas relações entre conhecimento e trabalho exigem capacidades de iniciativa e inovação e, mais do que nunca, 'aprender a aprender' num contínuo processo de educação permanente" (BRASIL, 1997, p.34).

Apesar da retórica da inovação que se apresenta tentando articular "saberes comunitários", estrutura "aberta" dos currículos escolares e ênfase na "conquista da pesquisa", com os desafios da escola em busca da Educação Integral, o que podemos constatar é a reapresentação de todos os aspectos que compõem o ideário escolanovista, com uma fundamentação no "construtivismo" piagetiano transformado em "neoconstrutivismo" (SAVIANI, 2011). Cabe ressaltar a crítica realizada por Saviani de que "a Escola Nova acabou por dissolver a diferença entre pesquisa e ensino, sem se dar conta de que, assim fazendo, ao mesmo tempo em que o ensino era empobrecido, se inviabilizava também a pesquisa" (SAVIANI, 2011, p.58).

A pedagogia do "aprender a aprender" apresenta também uma outra ressignificação, articulada à chamada "pedagogia das competências". No Mais Educação, essa perspectiva pode ser identificada quando os documentos norteadores vinculam o currículo intercultural ao alcance de metas relacionadas com habilidades e 
competências avaliadas pelo poder central. Assim, de acordo com o documento oficial:

Por estar vinculada ao alcance de metas para o desempenho escolar, a política de Educação Integral, em questão, é debatida em interface com a avaliação de desempenho nas habilidades expressas no domínio da língua portuguesa (com foco na leitura) e no domínio da matemática (com foco na resolução de problemas) por meio da Prova Brasil (BRASIL, 2009b, p.30).

Para Saviani, a "pedagogia das competências" apresenta-se como uma outra face da "pedagogia do aprender a aprender" (SAVIANI, 2011, p.473). Trata-se de uma reconfiguração do construtivismo, que, desde sua fonte originária e matriz teórica, identificadas com a obra de Piaget, mantém forte afinidade com o escolanovismo. De acordo com o autor, “[...] podemos mesmo considerar que se encontra aí a teoria que veio dar base científica para o lema pedagógico 'aprender a aprender"' (SAVIANI, 2011, p.434). Na perspectiva neoescolanovista, a ênfase das pesquisas de Piaget em relação ao desenvolvimento da inteligência humana dá lugar a uma retórica reformista que, aliás, guarda sintonia com a visão pósmoderna da "incredulidade em relação aos metarrelatos, em benefício de uma narrativa que obedece frequentemente à regra que lhe fixa a pragmática" (LYOTARD, 2002, p.38). ${ }^{8}$

Nesta linha de raciocínio, a questão da verdade fica elidida, o neoconstrutivismo funde-se ao neopragmatismo e as competências são assimiladas aos mecanismos de adaptação do comportamento humano ao meio material e social. Para isso, entram em cena as "competências cognitivas" e as "competências afetivo-emocionais". Saviani, então, resume tal elaboração da seguinte forma:

Em suma, a "pedagogia das competências" apresenta-se como a outra face da pedagogia do aprender a aprender, cujo objetivo é dotar os indivíduos de comportamentos flexíveis que lhes permitam ajustar-se às condições de uma sociedade em que as próprias necessidades de sobrevivência não estão garantidas. Sua satisfação deixou de ser um compromisso coletivo, ficando sob a responsabilidade dos próprios sujeitos, que, segundo a raiz etimológica dessa palavra, se encontram subjugados à "mão invisível do mercado" (SAVIANI, 2011, p.437). 
Com base nessas análises, não é de se estranhar que a lógica intercultural possa conviver e se fundir com o lógica produtivista do sistema de avaliação centrado no IDEB.

\section{As (im)possibilidades das Cidades Educadoras}

A preocupação em trazer a vida dos educandos para o espaço escolar, articulando escola e comunidade, constitui um ponto central do pragmatismo liberal de Jonh Dewey e Anísio Teixeira. Para eles, a escola deveria se configurar como uma "microssociedade", capaz de proporcionar o desenvolvimento de experiências democráticas.

No caso atual, para dar conta da interação escola-comunidade, o Mais Educação buscou ampliar a definição de instituição escolar, entendendo que esta "[...] compõe uma rede de espaços sociais (institucionais e não institucionais) que constroem comportamentos, juízos de valor, saberes e formas de ser e de estar no mundo" (MOLL, 2007, p.139). Nesse aspecto, o Mais Educação opera uma inversão em relação à proposta original do pragmatismo de Dewey, não apenas abrindo a escola, mas a estendendo para o "bairro-escola". Nessa perspectiva, a experiência democrática deve envolver outros espaços educadores no bairro e na cidade. Isso, na verdade, faz com que o Mais Educação se distancie de outras experiências históricas de educação integral desenvolvidas no Brasil, que se preocupavam com a ampliação física e a reconfiguração arquitetônica da escola. Na história da educação integral brasileira, a ampliação do tempo esteve sempre associada à ampliação do espaço, através da construção física das escolas e de grandes investimentos financeiros.

Porém, em um contexto de redução dos gastos ditados por um Estado neoliberal, esse caminho seria um verdadeiro sacrilégio ao credo hegemônico. Nesse sentido, entra em cena mais um movimento de ampliação/flexibilização do "espaço educativo". Cai bem, portanto, a solução de flexibilização dos espaços escolares, com o apoio das "redes sociais" e da "sociedade civil", sob a insígnia teórica de valorizar a "diversidade", porém representando mais uma forma de "economia de presença" do Estado.

Propor uma educação integral, com base nos conceitos de "cidades educadoras" e "territórios educativos", no Brasil, significa esquecer 
que, em muitos bairros de cidades brasileiras, principalmente no Norte e Nordeste do Brasil, o único equipamento público existente é a própria escola, sendo a precariedade uma de suas marcas principais. No caso das grandes metrópoles, a existência de equipamentos culturais públicos e privados não significa disponibilidade de horários, pessoal de apoio, equipamentos, produção, etc. A proposta de integrar ações de diversas secretarias municipais para transformar o território e a cidade em educadores esbarra na estrutura setorializada do Estado brasileiro e na cultura política patrimonialista, que está longe de ser superada. Assim, como ideia, a proposta de cidades educadoras é forte, mas requer um outro regime de colaboração, no qual os municípios tenham condições financeiras e políticas para implantar o projeto de educação em todos os cantos da cidade, mas fortalecendo a instituição escolar, como socializadora do conhecimento acumulado. Apelar para a oferta de espaços educativos através das redes da sociedade civil acaba sendo sinônimo de espaço precário para uma educação também precária.

O Mais Educação utiliza o argumento de que, para a elaboração de uma concepção contemporânea de Educação Integral, deve-se superar qualquer ideia de escola como instituição total que, como nos regimes de internato, controla e disciplina todo o processo educativo. No entanto, como veremos adiante, no processo de gestão do Programa, é o Governo Federal, influenciado pelas diretrizes dos organismos internacionais, o responsável pelo planejamento, deliberação e avaliação da execução do Programa em âmbito local. Assim, os instrumentos de controle, próprios das instituições fechadas, não são retirados quando a escola se estende para a comunidade, e sim reconfigurados para controlar o processo dentro e fora da escola, na extensão do território. Dessa forma, ao utilizarem o conceito foucaultiano de instituição total, os intelectuais petistas do Mais Educação ignoram que o Estado Capitalista, sob a égide do modelo gerencial, é uma instituição totalitária a serviço do mercado. Sua estratégia de gestão por resultados funciona a partir de uma lógica centralizado$\mathrm{ra}$, que se assemelha a um sistema prisional, que vigia e pune os estados e municípios que não atingirem as metas estabelecidas, tendo como instrumento os parcos recursos financeiros destinados pelo órgão central. 


\section{Gestão sistêmica, gerencial e neotecnicista}

A gestão intersetorial do Mais Educação não é uma invenção isolada em si mesma, mas possui nexos profundos com a lógica política imposta pelo PDE e deste com as novas formas de organização empresarial. $\mathrm{O}$ PDE foi lançado oficialmente em abril de $2007,{ }^{9}$ pelo Ministério da Educação, tendo como principal objetivo melhorar a qualidade da educação no Brasil, a partir da implantação de uma visão sistêmica de gestão. Conforme afirmou o próprio presidente Lula, no ato de lançamento, o PDE teria o mesmo valor do "Plano de Aceleração do Crescimento" (PAC).

Composto por mais de 40 programas/ações dispostos em quatro grupos (educação básica, superior, educação profissional e alfabetização), o PDE, através de uma visão sistêmica, busca superar falsas oposições entre os diversos níveis e modalidades do ensino. Nesse sentido, essa visão sistêmica implica "[...] reconhecer as conexões intrínsecas entre educação básica, educação superior, educação tecnológica e alfabetização e, a partir dessas conexões, potencializar as políticas de educação de forma a que se reforcem reciprocamente" (BRASIL, 2007a, p.10).

Essa visão sistêmica se pauta pela perspectiva de possibilitar o aperfeiçoamento do regime de colaboração, concebido como o compartilhamento, entre os entes federados, "[...] de competências políticas, técnicas e financeiras para a execução de programas de manutenção e desenvolvimento da educação, de forma a consertar a atuação dos entes federados sem lhes ferir a autonomia" (BRASIL, 2007a, p.10). Tal abordagem apresenta ainda dois outros imperativos: a responsabilização (que se conhece na literatura como accountability) e a mobilização da sociedade como dimensões indispensáveis de um plano de desenvolvimento da educação.

[...] a organização é vista em contínua mudança, na medida em que só sobrevive e se desenvolve quem se adapta a um ambiente em constante mutação. [...] Esse processo implica que o sistema articule e combine formas organizacionais e produtivas bastante diversificadas dentro de uma mesma estratégia global (BRUNO, 2009, p.31).

Nesta perspectiva, administrar é, sobretudo, "administrar as inter-relações" entre organizações, sendo fundamental conhecer os condicionamentos recíprocos dessas inter-relações. Entretanto, essa aparente 
descentralização não dispensa os processos de centralização. Ao contrário, leva ao reforço e à diversificação dos mecanismos de controle, através dos quais se desenvolvem as políticas de prevenção de conflitos e a construção de consenso. Assim, as reformas das organizações encaminham-se para: "[...] a criação de pequenas unidades descentralizadas, com autonomia local, conectadas por laços mais ou menos frouxos ao núcleo central da organização, que exerce o controle global, através de canais de comunicação e informação e da distribuição de recursos" (BRUNO, 2009, p.37).

Quanto às relações entre classes no interior das organizações, a participação proposta aos trabalhadores resulta da compreensão do patronato de que as novas gerações de trabalhadores apresentam outro elemento a ser explorado: a sua capacidade de raciocínio.

Com a reestruturação do trabalho em curso, a partir da introdução das formas sistêmicas de organização do trabalho, das novas técnicas de produção (microeletrônica e informática), é cada vez mais a capacidade de pensar do trabalhador que se buscar explorar. E não é qualquer forma de pensar, por isso, trata-se de disciplinar a estrutura psíquica dos trabalhadores, para que seu raciocínio desenvolva-se primordialmente, consoante a "cultura organizacional" da empresa, e a sua subjetividade opere no sentido de envolvê-lo com os objetivos da organização (BRUNO, 2009, p.39).

É exatamente por isso que a escola na atualidade é de grande interesse dos homens de negócio, sendo objeto de tantas discussões e propostas de reestruturação. Ao lado da família e do meio social mais amplo, a escola é uma das esferas de produção de capacidade de trabalho, não podendo mais permanecer ao largo dos mecanismos de controle social e econômico do capitalismo. Além do mais, o custo dessa produção precisa ser racionalizado, tal qual qualquer outra mercadoria.

Em todo o mundo, constatamos reformas educacionais caracterizadas por uma descentralização administrativa, envolvendo uma maior participação dos sujeitos no processo educacional no interior da escola e aumentando proporcionalmente suas responsabilidades com a descentralização financeira e operacional. Ao mesmo tempo, constatamos o aumento do controle pelo órgão focal, que se dá basicamente através da distribuição de recursos, da definição e do controle dos meios de acompanhamento e avaliação de resultados, dos canais de distribuição de infor- 
mações, dos padrões gerais de funcionamento das unidades escolares, ditando os limites em que elas devem operar e promovendo as adaptações necessárias para o bom funcionamento do sistema educacional como um todo.

O fundamental mesmo é potencializar a utilização dos meios físicos que integram o processo de trabalho dos educadores (instalações, livros, material didático, equipamentos, etc.), de intensificação de suas atividades, sem despender grandes investimentos em capacitação de professores. Aliás, em relação ao Brasil, o Banco Mundial propõe que os investimentos em educação privilegiem os meios físicos e os equipamentos em detrimento do professor. Conforme Bruno (2009), a justificativa do Banco Mundial é que

[...] investir em Recursos Humanos, no caso, professores da rede pública, em termos de capacitação, condições de trabalho, provocaria uma valorização social desses profissionais do setor público, tornando-os muito reivindicativos, o que, certamente, segundo o Banco Mundial, desencadearia um novo processo inflacionário. Resta saber como é possível melhorar a qualidade do ensino público, sem investimento na qualificação permanente de professores e demais profissionais da educação (BRUNO, 2009, p.42).

Por outro lado, os grandes investimentos para a melhoria do ensino são localizados naquelas regiões onde a classe trabalhadora é capaz de realizar um trabalho mais complexo, setores que competem com os seguimentos mais inovadores e produtivos da economia mundial, mais uma vez adequando o sistema educacional à heterogeneidade do sistema econômico mundial. Essa dinâmica reproduz uma nova segmentação e hierarquização da classe trabalhadora mundialmente, dividindo-a em qualificados/não qualificados/precários/autônomos/desempregados.

De acordo com Bruno, "[...] isto talvez indique que, na nova divisão internacional do trabalho, o Brasil vem sendo pensado como um país de economia predominantemente informal, especializada na produção de bens e serviços, pouco complexos e de baixo valor agregado" (BRUNO, 2009, p.43).

Ao vislumbramos a lógica de operacionalização do PDE, através do "Programa de Metas Todos pela Educação", não resta dúvida de que a opção pela lógica sistêmica é a que pretende transportar o modelo empresarial para a educação. Conforme Camini, “[...] os entes federados 
foram convidados pelo MEC a aderir à proposta, estabelecendo parceria, a qual se traduzia em compromisso que implica assumir as diretrizes já estabelecidas no decreto Federal no 6.094/2007" (CAMINI, 2010, p.539). Entretanto o elemento essencialmente definidor do modelo sistêmico foi a contribuição do movimento empresarial Todos pela Educação, que,

[...] se constituiu, de fato, como um aglomerado de grupos empresariais com representante e patrocínio de entidades como o Grupo Pão de Açúcar, Fundação Itaú Social, Fundação Bradesco, Instituto Gerdau, Grupo Gerdau, Fundação Roberto Marinho, Fundação Educar - Dpaschoal, Instituto Itaú Cultural, Faça Parte - Instituto Brasil Voluntário, Instituto Ayrton Senna, Cia Suzano, Banco ABN - Real, Banco Santander, Instituto Ethos, entre outros (SAVIANI, 2007, p.375).

Analisando a lógica de gestão que perpassa o PDE, Freitas (2012) afirma que esta se apresenta com o que denomina de "neotecnicismo" ou uma "teoria da responsabilização", meritocrática e gerencialista, em que se propõe uma racionalidade técnica na forma de standards, "[...] expectativas de aprendizagem medidas em testes padronizados, com ênfase nos processos de gerenciamento da força de trabalho da escola (controle pelo processo, bônus e punições) (FREITAS, 2012, p.383). Segundo o autor, esse modelo ancora-se na psicologia behaviorista, fortalecida pela econometria, ciências da informação e de sistemas, elevadas às condições de pilares da educação contemporânea.

A gestão do Programa Mais Educação é um exemplo de que tais orientações podem mudar de forma, sem alterar o conteúdo. No entanto, duas questões são centrais no modelo de gestão do Mais Educação: apesar de preconizar instâncias descentralizadas de gestão (os fóruns interministeriais, metropolitanos e locais), a centralidade do IDEB na avaliação dos resultados e o condicionamento da liberação de recursos à assinatura do "Plano de Metas Todos Pela Educação" revelam o alinhamento do programa ao modelo gerencialista neoliberal.

Podemos então caracterizar mais uma ressignificação, porém, agora, do tecnicismo para o neotecnicismo. Conforme Saviani, as máximas do tecnicismo são os princípios da "racionalidade, eficiência e produtividade, dos quais deriva o corolário relativo à obtenção do máximo resultado com o mínimo de dispêndio" (SAVIANI, 2011, p.438). Entretanto, a partir da década de 1990, esse objetivo deixa de ser iniciativa, controle e 
direção direta do Estado, advogando-se a "[...] valorização dos mecanismos de mercado, o apelo à iniciativa privada e às organizações não governamentais" (SAVIANI, 2011, p.438). Saviani ressalta ainda que as diversas reformas educativas levadas a cabo em diferentes países têm um ponto comum: "[...] o empenho em reduzir custos, encargos e investimentos públicos, buscando, senão transferi-los, ao menos dividi-los com a iniciativa privada e as organizações não governamentais" (SAVIANI, 2011, p.438).

\section{Considerações finais}

O Programa Mais Educação vem ganhando cada vez mais status de ação estratégica no Governo Lula/Dilma, no intuito de construir uma "visão contemporânea" de Educação Integral. Entretanto, falar em construção de uma "concepção contemporânea" de Educação Integral não revela o projeto ético-político ao qual o Mais Educação está articulado. Do ponto de vista da emancipação humana, o desvelamento das concepções político-pedagógicas e de gestão que orientam o Programa Mais Educação nos levou a considerá-lo uma regressão no plano teórico e social, em função da subordinação intelectual e moral dos Governos Lula/Dilma aos organismos multilaterais, apesar da relativa originalidade e particularidade na forma como tal subordinação está sendo produzida.

Em relação aos fins do projeto político-pedagógico, constatamos que a equação "proteger e educar", que é uma das justificativas para a ampliação da jornada escolar, ao invés de superar as experiências passadas, renova e aprofunda a ideia de "educação compensatória", "robustecendo" a escola com uma série de tarefas não propriamente educativas, que só podem gerar sobrecarga e intensificação do trabalho dos educadores e encurtar a sua função social de socialização do conhecimento historicamente acumulado. Isso porque a ampliação da jornada escolar não vem acompanhada da garantia das condições de trabalho adequadas, sendo a maior parte das responsabilidades repassadas aos estados e municípios, que são, na sua grande maioria, detentores de parcos orçamentos. $\mathrm{Na}$ precariedade, a função de "proteger" prevalece em relação à de educar, resultando, muito mais, na responsabilização da escola e dos educadores pela "guarda" de crianças e adolescentes. Ou seja, prevalece a polí- 
tica do "disciplinamento da pobreza", tarefa atribuída à escola nos países subdesenvolvidos, conforme recomendações do Banco Mundial, desde a década de 1990.

Para dar conta dessa tarefa, nada mais adequado do que uma pedagogia que não venha questionar os interesses do capital. Uma pedagogia do consenso. A Educação Integral/Intercultural, nesse sentido, renova o ideário da vertente pragmatista da Pedagogia Nova, tentando transformar a escola em um espaço de diálogo inter/transcultural, disseminando um clima antiessencialista e anti-humanista, restringindo a escola a um espaço de políticas afirmativas das diferenças de gênero, raciais, etc., dissimulando, ainda mais, sua capacidade de instrumentalizar as novas gerações para o exercício de crítica ao sistema capitalista. A outra face da Pedagogia do Mais Educaşão é a Pedagogia das Competências, explícita nos PCNs e principalmente no sistema de avaliação voltado para a melhoria do IDEB. Assim, a Pedagogia do Mais Educaşão se apresenta com "dupla face": de um lado, a Pedagogia das Diferenças desvia a escola das questões essenciais para a luta de classes e crítica ao capitalismo, relegando a mesma ao espaço de negociações sofismáticas das diferenças culturais; de outro, a Pedagogia das Competências se afirma na formação da novas gerações para o mercado de trabalho e para a empregabilidade.

A articulação dessa "dupla face" se dá através da Visão Sistêmica de gestão, disseminada pelo PDE e com presença marcante nos textos que orientam a gestão do Mais Educação. A visão sistêmica, como buscamos desvelar, é o modelo que está orientando a reengenharia das empresas transnacionais, frente ao processo de internacionalização da economia, mas fundamenta o PDE/Programa de Metas Todos pela Educação/Programa Mais Educação, o que demonstra uma presença decisiva dos homens de negócio na direção intelectual e moral do Governo Lula/Dilma, como é o caso do "Movimento Todos pela Educação".

Dessa forma, o Programa Mais Educação, no âmbito da política educacional, é expressão particular de uma concepção política que visou "executar o programa de combate à pobreza dentro da ordem" (SINGER, 2012, p.74). A respeito dessa concepção política que orientou os governos Lula e continua a guiar o mandato de Dilma, André Singer, porta-voz durante os quatro primeiros anos do governo Lula, argumenta que o objetivo central do Governo Lula, desde 2003, foi o de, “[...] contando com a mudança da conjuntura econômica internacional, a adoção de políticas 
para reduzir a pobreza - com destaque para o combate à miséria - e para ativação do mercado interno, sem confronto com o capital" (SINGER, 2012, p.13, grifos do autor). De acordo com o autor, essa orientação já estava presente na Carta aos Brasileiros - um documento/compromisso elaborado, em nome de Lula, poucas semanas antes das eleições de 2002, afirmando que, se eleito, manteria a agenda macroeconômica em curso no governo Cardoso, respeitando todos os contratos elaborados no período do neoliberalismo duro.

Com ressalvas aos relativos avanços no campo da política social, os governos Lula/Dilma não apenas assumiram prioritariamente o lado dos empresários no âmbito da política econômica, como também, nas formulações da "concepção contemporânea" para a Educação Integral, fundamentando-a na teoria pós-moderna/pós-estruturalista, que, associada à teoria do capital humano, renovada pela pedagogia das competências, constitui uma nova epistemologia da hegemonia do capitalismo flexível no Brasil.

Dessa forma, o Programa Mais Educaşão, no que se refere à concepção de "educação integral intercultural e intersetorial", apresenta uma inovação, que expressa dupla regressão da teoria social e educacional que estamos vivendo no plano mundial e também nacional. Conforme Frigotto (2009), no âmbito da teoria econômica e social, a regressão se dá através da hegemonia do neoliberalismo, doutrina que regride ao credo do liberalismo conservador e que "[...] assenta a política econômica e social num receituário que anula as conquistas parciais do projeto keynesiano, cujo objetivo foi corrigir, na ótica capitalista, o credo liberal conservador" (FRIGOT'TO, 2009, p.67).

Concomitantemente, a outra regressão se dá no campo das ciências sociais, com a influência do ideário do pós-moderno no campo educacional, que renova o pragmatismo escolanovista (neoescolanovismo) e, por conseguinte, se mescla ao tecnicismo, renovado pela Pedagogia das Competências (neotecnicismo). Pós-modernismo este que é uma expressão cultural do capitalismo tardio, marcado pela fragmentação da realidade, da produção flexível e da mutilação de direitos da classe trabalhadora e da hipertrofia do consumismo, da competição e do individualismo (JAMESON, 1996). No campo das concepções educacionais, essa dupla regressão se expressa na ideologia da "sociedade do conhecimento", das "competências" e da "empregabilidade". Para Frigotto (2009), o pós- 
modernismo, no plano educacional, é traduzido por um ideário em que não há lugar para todos, e o problema não é coletivo, mas individual. Dessa forma, as competências deverão ser desenvolvidas de forma a garantir a empregabilidade.

Conclui-se, portanto, que os governos Lula/Dilma, ao elaborarem uma "concepção contemporânea de educação integral", através do Programa Mais Educação, por uma questão de subordinação intelectual e moral, tomaram emprestado a concepção de mundo de um pensamento de direita para fundamentar sua política. As inovações apresentadas pelos intelectuais gestores da política educacional do Governo Federal se baseiam em teorias que se apresentam como de esquerda, mas que servem muito mais para legitimar os processos de reconfiguração da educação ao modo de acumulação flexível do capitalismo. Assim, o Mais Educação participa do que Oliveira (2010) denominou de Hegemonia às Avessas, ou seja, os dominantes, os capitalistas, consentem que a educação seja conduzida pelos dominados (representados pelo governos Lula/Dilma), desde que a "direção moral" não questione a forma de exploração capitalista. 


\section{NOTAS}

1 Também constituem a Base Legal do Programa os seguintes ordenamentos: Constituição Federal (1998), Estatuto da Criança e do Adolescente (1990), Lei de Diretrizes e Bases da Educação Nacional (1996), do Programa Mais Educação, as Resoluções do Fundo Nacional de Desenvolvimento da Educação (FNDE) nº 38/09 e $n^{\circ}$ 67/09 (ambas referentes ao Programa Nacional de Alimentação Escolar (PNAE)/Mais Educação e a de n ${ }^{\circ}$ 20/11, que dispõe sobre a destinação de recursos financeiros para que seja ampliada a jornada escolar para, no mínimo, sete horas diárias. Compõe, ainda, o leque normativo do Programa em destaque a Portaria Normativa $n^{\circ}$ 19, de 26 de abril de 2007, que institui a parceria entre o Ministério da Educação (MEC) e o Ministério do Esporte (ME), para a construção de quadras esportivas, a Lei $\mathrm{n}^{\circ}$ 11.494/07 (Lei do Fundeb), que prevê a Educação Integral, a Lei no 11.947/09 (PNAE/Mais Educação) e o Manual da Educação Integral/Programa Dinheiro Direto na Escola (PDDE).

2 Esta proposta foi aprovada pela comissão especial da Câmara de Deputados Federais no dia 24 de novembro de 2010 e valerá para a educação infantil e para os ensinos fundamental e médio regulares, prevendo também atividades extraclasses opcionais, após o cumprimento das sete horas mínimas obrigatórias. Atualmente, a PEC 134 ainda se encontra em tramitação no Congresso Nacional.

3 Este artigo é parte da pesquisa Educação Integral no Contexto da Intersetorialidade: avaliando a implementação do Programa Mais Educação em Pernambuco, financiada pelo CNPq através do edital 02/2009 - Ciências Humanas, Sociais e Sociais Aplicadas.

4 Como o Caderno Bairro Escola Passo a Passo, da Associação Escola Aprendiz/MEC/UNICEFE/Prefeitura de Belo Horizonte/Prefeitura de Nova Iguaçu e BRASIL. Manual de rede de educação para a diversidade. Brasília: MEC/Secad, 2010, entre outros.

5 A operacionalização do PDE é feita pelo Plano de Metas Compromisso Todos pela Educação (Decreto n ${ }^{\circ}$ 6.094/2007). Assinado o "Termo de Compromisso Todos pela Educação", estados e municípios assumem compromisso com a implementação das 28 diretrizes estabelecidas. Após adesão, o ente federativo tem a tarefa de fazer o diagnóstico da situação educacional da rede e a elaboração do "Plano de Ações Articuladas" (PAR). Daí por diante, o monitoramento e a avaliação são realizados pela Secad, através do Sistema Integrado de Acompanhamento das Ações do MEC (Simec).

6 SAVIANI, D. Escola e democracia. Campinas: Autores Associados, 1983.

7 O Relatório Jaques Delors (2006) define como os quatro pilares básicos para a educação no século XXI os seguintes: aprender a conviver; aprender a conbecer; aprender a fazer; aprender a ser (DELORS, 2006, p.12-14).

8 Nesse discurso neoconstrutivista, “[...] tão disseminado nos dias de hoje, são pouco frequentes as menções aos estádios psicogenéticos (sensório-motor, pré-operatório, operatório concreto, operatório formal). Diz-se que, recordando as quatro diferenças estabelecidas por Piaget entre as inteligências sensório-motora e conceitual mencionadas por 
Zélia Ramozzi-Chiarottino, a primeira predomina” (SAVIANI, 2011, p.436). A retórica neoconstrutivista "funciona como um filme em câmara lenta que representaria uma imagem imóvel depois da outra, em vez de chegar a fusão de imagens; tende ao êxito e não à verdade: encontra sua satisfação na conquista do fim prático perseguido e não a construção ou a explicação" (RAMOZZI-CHIAROTTINO, 1984, p.58 apud SAVIANI, 2011, p.436).

9 De acordo com a publicação do Plano de Desenvolvimento da Educação: Razões, Princípios e Programas (MEC, 2007), o PDE parte do Plano Nacional de Educação e avança nas ações relacionadas a melhoria da qualidade da educação. Conforme documento do MEC a vantagem do PDE é a de ser um plano executivo que "[...] visa dar consequência as metas quantitativas estabelecidas naquele diploma legal” (PNE, p. 07). De acordo com Saviani (2007) a despeito de as ações do PDE incidirem sobre aspectos do PNE, este primeiro não pode ser considerado um plano pois não parte do diagnóstico, das diretrizes, dos objetivos e metas definidas pelo PNE. O PDE, segundo o autor, tem mais um caráter de programa de ação, pois lhes faltam elementos fundamentais que caracterizam um plano.

\section{REFERÊNCIAS}

ALGEBAILE, E. B. Escola pública e pobrez̧a no Brasil: ampliação para menos. Rio de Janeiro: Lamparina, FAPERJ, 2009.

BARKER, M.; BEEZER, A. Qué hay en un texto? In: BARKER, M.; BEEZER, A. (Orgs.). Introducion a los estudios culturales. Barcelona: Bosch Casa Editorial, 1994. p.07-27. BRASIL. MEC. Plano de Desenvolvimento da Educação (PDE). Brasília, 2007a.

BRASIL. Proposta de Emenda Constitucional n. 134 (em tramitação). Brasília, 2007b.

BRASIL. Portaria Interministerial n¹7, de 24/04/2007, Brasília, 2007c.

BRASIL. Plano de Metas Compromisso Todos pela Educação. Decreto n ${ }^{\circ} 6.094$ de 24/04/2007, Brasília, 2007d.

BRASIL. Programa Mais Educação: Gestão Intersetorial no Município. Brasília, 2008.

BRASIL. Programa Mais Educação: Gestão Intersetorial no Território. Brasília, 2009b.

BRASIL. Educação Integral: texto de referência para o debate nacional. Brasília, 2009c.

BRASIL. Rede de Saberes Mais Educação: pressupostos para Projetos Pedagógicos de Educação integral. Brasília, 2009d.

BRASIL. Projeto de Lei no 8.035 - PNE (2010-2020) - em tramitação. Brasília, 2010a.

BRASIL. Decreto n 7.083 , de 27 de janeiro de 2010. Brasília, 2010b.

BRUNO, L. Poder e administração no capitalismo contemporâneo. In: OLIVEIRA, D.

A. (Org.). Gestão democrática da educaşão. Petrópolis: Vozes, 2009. p.14-45.

CAMINI, L. A política educacional do PDE e do Plano de Metas Todos pela Educação. Revista Brasileira de Política e Administração da Educação (RBPAE), Associação de Política e Administração da Educação, Porto Alegre, v.26. n.3, p.409-640, set./dez. 2010.

DELORS, J. (Presidente). Educação: um tesouro à descobrir. Relatório para UNESCO da comissão internacional da educação para o séc. XXI. Paris: UNESCO, 2006 
DUARTE, N. Vygotsky e o "aprender a aprender”: crítica às apropriações neoliberais e pósmodernas da teoria vigotskiana. São Paulo: Autores Associados, 2001.

DELLA FONTE, S. S. Fundamentos teóricos da pedagogia histórico-crítica. In: MARSIGLIA, A. C. G. (Org.). Pedagogia histórico-crítica: 30 anos. Campinas: Autores Associados, 2011. p.23-42.

DELLA FONTE, S.; LOUREIRO, R. Educação escolar e o multiculturalismo intercultural: crítica a partir de Simone de Beauvoir. Pro-Posições, Campinas, v.22, n.3 (66), p.177193, set./dez. 2011.

EAGLETON, T. De onde vêm os pós-modernistas? In: WOOD, E. M.; FOSTER, J. B. (Orgs.). Em defesa da história. Marxismo e pós-modernismo. Trad. Ruy Jungmanm. Rio de Janeiro: Jorge Zahar, 1999. p.23-42.

ECO, H. Obra aberta. São Paulo: Perspectiva, 2007.

ESCOSTEGUY, A. C. Estudos culturais: uma introdução. In: SILVA, T. T. da. O que é, afinal, estudos culturais. 4.ed. Belo Horizonte: Autêntica, 2010. p.133-166.

FOUCAULT, M. Vigiar e punir: o nascimento da prisão. Petrópolis: Vozes, 1987.

FREITAS, L. C. de. Os reformadores empresariais da educação: da desmoralização do magistério à destruição do sistema público de educação. Revista Educação e Sociedade, Campinas, v.33, n.119, p.379-404, abr./jun. 2012.

FERREIRA, E. B.; OLIVEIRA, D. A. (Orgs.). Crise da escola e politicas educativas. Belo Horizonte: Autêntica, 2009.

FRIGOTTO, G. Política e gestão educacional na contemporaneidade. In: FERREIRA, E. B.; OLIVEIRA, D. A. Crise da escola e politicas educativas. Belo Horizonte: Autêntica, 2009. p.65-80.

GRAMSCI, A. Concep̧cão dialética da história. Rio de Janeiro: Civilização Brasileira, 1978.

GADOTTI, M. Educação integral no Brasil: inovações em processo. São Paulo: Instituto Paulo Freire. 2009.

JAMESON, F. Pós-modernismo: a lógica cultural do capitalismo tardio. São Paulo: Ática, 1997.

LYOTARD, J.-F. A condição pós-moderna. São Paulo: José Olympio, 2002.

MALIK, K. O espelho da raça: o pós-modernismo e a louvação da diferença. In: WOOD, E. M.; FOSTER, J. B. (Orgs.). Em defesa da história: marxismo e pós-modernismo. Trad. R. Jungmanm. Rio de Janeiro: Jorge Zahar, 1999. p.123-144.

MOLL, J. Da crise da escola e do seu (re)encontro com a vida. In: QUIJANO, G. M. R. (Org.). Jornada da educação popular pelo encontro da escola com a vida. Porto Alegre: UFRGS, 2007. p.59-69.

MULLER, P. Un schema d'analyse des politiqueiros sectorielles. Revue Française de Science Politique, Paris, v.35, n.2, p.165-189, 1985.

OLIVEIRA, F. de; BRAGA, R.; RIZEK, C. Hegemonia às avessas. São Paulo: Boitempo, 2010 .

PINHEIRO, F. P. da S. Z. O Programa Mais Educação: uma concepção de Educação Integral. 135f. 2009. Dissertação (Mestrado em Educação) - Centro de Ciências Humanas e Sociais, Unirio/RJ, Rio de Janeiro, 2009.

RAMOS, M. N. A pedagogia das competências: autonomia ou adaptação? São Paulo: Cortez, 2011.

SAFATLE, V. A esquerda que não teme dižer seu nome. São Paulo: Três Estrelas, 2012. 
SANTOS, B. de S. Um discurso sobre as ciências. São Paulo: Cortez, 1998.

SAVIANI, D. Escola e democracia. Campinas: Autores Associados, 2008.

SAVIANI, D. História das ideias pedagógicas no Brasil. Campinas: Autores Associados, 2011

SAVIANI, D. A pedagogia crítica e a defesa do ensino público. Revista Caros Amigos, Especial Educação, Sumaré, SP, p.7, jun. 2011.

SILVA, S. R. da. A educação frente as tendências liberal e comunitarista da democracia. Linhas Críticas, Brasília, v.15, n.28. p.153-169, jan./jun. 2009.

SINGER, A. V. Os sentidos do lulismo: reforma gradual e pacto conservador. São Paulo: Companhia das Letras, 2012.

TEIXEIRA, A. A propósito da "escola única". Revista do Ensino, Salvador, v.1, n.2, p.3, 1924.

WOOD, E. M. O que é a agenda pós-moderna. In: WOOD, E. M.; FOSTER, J. B. (Orgs.). Em defesa da história: marxismo e pós-modernismo. Trad. R. Jungmanm. Rio de Janeiro: Jorge Zahar, 1999. p.7-22.

Recebido em: 23/03/2013

Aprovado em: $26 / 11 / 2013$

Contato:

Universidade Federal de Pernambuco

Centro Acadêmico do Agreste

Rodovia BR 104, km 59

Nova Caruaru

CEP 55014-900

Caruaru | PE | Brasil 
